\title{
Lingering death after treatment withdrawal in the neonatal intensive care unit
}

\author{
H E McHaffie, A J Lyon, P W Fowlie
}

\begin{abstract}
Objective-To explore parents' perceptions of treatment withdrawal and the dying process.

Design-Face to face interviews with 59 sets of parents of 62 babies in the East of Scotland three months and 13 months after death.

Results-22\% of the parents expressed reservations about the length of the dying process, which they reported in these instances had taken from three to 36 hours. Deaths that medical teams had predicted would be quick had, according to the parents' recollections, taken from 1.5 to 31 hours. When a baby died swiftly, this seemed to confirm the wisdom of the decision to stop. When babies lingered, doubts were raised.

Conclusions-Parents need to be adequately prepared for what may happen after treatment withdrawal. The debate should be reopened about the best way to manage protracted deaths in line with parental need.

(Arch Dis Child Fetal Neonatal Ed 2001;85:F8-F12)
\end{abstract}

Keywords: protracted deaths; withdrawal of treatment; bereaved parents; neonates

Survival of sick and preterm infants has improved dramatically with the development of neonatal intensive care. In some circumstances, however, it is clear that the prolongation of aggressive invasive treatment is not in the best interests of the baby. Reorientation of treatment to compassionate care is accepted practice in some situations, and these have been outlined in the Royal College of Paediatrics and Child Health (RCPCH) framework for practice, ${ }^{1}$ and further discussed in the BMA's guidance to clinicians. ${ }^{2}$

Official documents underline both professional $^{12}$ and political ${ }^{3}{ }^{4}$ rejection of euthanasia, but withdrawal of intensive treatment means that the baby is expected to die. Management is orientated towards facilitating a death that is dignified and free from suffering. The parents also need help with this distressing experience but there is little guidance available to staff on how to manage these situations. A previous study of doctors and nurses who deal with such families showed that teams evolve their own ways of coping, but practice varies considerably. $^{5}$

Moving accounts of the conflicts and pain for individual parents facing these distressing experiences in the United States have been provided by observational studies carried out by people not previously conversant with neonatal intensive care, such as social scientists or journalists. ${ }^{6-9}$ The lived reality has been captured anecdotally by parents describing their own reactions and emotions. ${ }^{10-13}$ Clearly, the time between withdrawal of intensive treatment and the death of the baby is very variable, and many parents and professionals have found the uncertainty difficult to deal with.

This paper presents findings from a multicentre study that aimed to establish the effects of current practices on the families of babies from whom intensive care had been withdrawn or withheld. It focuses on the parents' perceptions of the length of time it took for their baby to die.

\section{Method}

SETTING

The study units were three regional neonatal referral centres in the East of Scotland selected to include a range of populations drawn from island as well as mainland families, rural as well as urban, local as well as those referred from a distance, and all social classes. Ethical committee approval was obtained for each centre.

SAMPLE

Families were eligible for inclusion if there had been any discussion about treatment limitation. The babies were those for whom there was a medical prognosis of either early death or severe impairment associated with a very poor quality of life. All three main categories of imperilled babies were represented: premature delivery, congenital anomalies, perinatal asphyxia. Fifty nine $(73 \%)$ of the 81 families who met the eligibility criteria were recruited. Of the 22 who were lost to the study, 11 declined to participate and 11 were not told about the study because they did not wish any follow up, the hospital had lost contact with them, or in one case they were considered unsuitable for inclusion.

\section{PROCEDURE}

Parents were recruited at the time of first follow up bereavement clinic appointments. Interviews were scheduled to take place three and 13 months after the death of the baby using semistructured schedules designed for the purpose, although in reality some first interviews were delayed because parents were recalled later. The topics under investigation were parents' perceptions of their whole experience of this pregnancy, birth, decision making, death, and first year of bereavement. They lasted 1-5.25 hours and were all recorded on tape. Three quarters of the parents (44/59) were 
interviewed as a couple at the first point of enquiry and $80 \%(40 / 50)$ at the second.

Data were entered on to a computer under predetermined variable names, the wide range of responses being added as values to ensure no point was omitted. SPSS for the Apple Mac was used to analyse the resulting large volume of data. To ensure scientific rigour, $12 \%$ of the interviews were independently checked for accuracy of coding and the intepretation of content by a practising paediatrician (PWF) and a further $10 \%$ by a student in medical ethics ( $\mathrm{R}$ Bercovitch). These checks showed that three different listeners heard and understood the parents in the same way.

RESPONDENTS

A total of 59 families (108 parents) participated at three months, and $85 \%$ of them (50 families; 90 parents) again at 13 months. At the time of first interview, $91 \%$ of the couples were living together. Most of the parents were in their thirties or older $(60 \%$ mothers, $67 \%$ fathers). Only $8 \%$ of the mothers and no fathers were in their teens. Thirty one percent of the mothers were primigravidae. The remaining $69 \%$ had had from one to five other pregnancies.

There were eight multiple pregnancies: twins, triplets, and quads. Of the 16 babies born alive from these pregnancies, 11 were eligible for inclusion in the study. This gives a total of 62 babies in the study, with gestations of 22-41 weeks, of which nine were less than 24 weeks. All the babies died, most (61\%) within the first week of life, but $10 \%$ lived for more than three months. One child survived for almost nine months.

\section{Results}

It is important to bear in mind that all recorded comments are the parents' own perceptions. No attempt was made to obtain independent corroboration.

CONTEXT

Two factors set an overall context within which our findings are to be understood: parents want to be involved, and they are generally very satisfied with the management they and their baby received. We outline these and include a flavour of the reality of the situation before describing the results.

Involvement in the dying process

All except three families had opportunity to be involved in the dying process. The babies of the three who did not, died before their parents arrived in the unit. Not all of those who had the chance to be involved, however, availed themselves of all the opportunities this offered. One family did not participate in any way. A further five sets of parents had only limited involvement. One couple with a severely asphyxiated baby just wanted to be told if he deteriorated but could not face watching him die. Another left before the death of premature twins because they believed they had already in effect died. A third couple remained convinced their child would survive and, not wanting to jeopardise her chances, they refused to have her out of the incubator to cuddle until the last few minutes of life. However, overall the parents conveyed a strong message both soon after the event and a year later, that, even though it was traumatic, they valued the experience of being with their child at this time. In most cases, both parents were involved in the dying. In three cases only the mother was, and in one case only the father.

\section{Overall satisfaction with the management of the} dying

At the first point of enquiry roughly three months after the death, just over two thirds $(40 / 59,68 \%)$ of the sets of parents were satisfied overall with the way the dying process had been handled. For a further $14(24 \%)$, it had been largely satisfactory but they could identify areas for improvement. For five $(8 \%)$ it was rated unsatisfactory.

Asked to reflect back 13 months after the event, $72 \%$ (36/50) felt the management of their case had been as good as it could have been under these tragic circumstances. Just over a quarter $(14,28 \%)$ expressed continuing dissatisfaction or reservations. On comparing data at both points of enquiry, it emerged that six families who had expressed early dissatisfaction, a year on had no lasting regrets. Three who had been dissatisfied at first interview were not available for comment at 13 months. However, five sets of parents were less satisfied on mature reflection than they had been initially.

\section{The reality}

To illustrate something of the variety of circumstances in which these deaths occur, we offer three brief vignettes drawn from the parents' own accounts of what they experienced.

After treatment withdrawal, the parents of one severely asphyxiated baby had her in a quiet room with them for 36 hours before she died. Again and again they said their goodbyes. Utterly exhausted, during the night they drifted into sleep themselves expecting the child would be dead when they awoke. But she survived two whole nights. As time went on, they began seriously to question the decision to let her die. On the third morning, unable to bear more, they felt they would have to leave the hospital. However, they lingered a while and were still present when she did eventually die.

Another child with a combination of anomalies deteriorated slowly over six weeks. Her parents had initially dreaded the time she would need to be given morphine, seeing this as the beginning of the end. But the child appeared much improved and she remained on it for the rest of her life. Her parents even took her home for a brief time before a setback necessitated readmission. Once in hospital again, her condition deteriorated further and she became totally unresponsive. The family prepared themselves for her death. Cheyne Stokes breathing signalled the final phase. Then suddenly the child rallied and began to play with her parents. The mother was distraught and told the consultant she could 
not go through this process again. On this occasion, however, the baby continued to deteriorate and died soon afterwards.

Against medical predictions, a third child with lethal cardiac anomalies survived the first two attempts to withdraw treatment (being taken off the ventilator and having prostaglandins stopped). On each occasion the parents prepared themselves for her death, but each time she lived. Her parents eventually took her home for several weeks. They returned often for morphine injections, being told each time, the parents recalled, that these might kill her. When she was finally ill enough to be readmitted to hospital, the parents did not believe the staff's prediction of imminent death; she had defied expectations before, she would again. In consequence her death stunned them.

These were just three of the cases we studied, in many ways atypical of the whole sample, but illustrative of the impact these events have on families. Elements that concern parents are instructive, but should be set against the context already outlined above. In the following discussion we provide a broader picture.

DURATION OF THE DYING PROCESS

More than a fifth $(13 / 59,22 \%)$ of the families found the length of time it took their baby to die a significant source of distress. Given the poor condition of the child and the bleak prognosis, they had expected the process to be swift. Indeed one couple said they believed that death would be instantaneous when the ventilator was withdrawn and they were completely unprepared for the 21 hours they had with the living child. For four of the 13, the dying had taken three to six hours; for three, it was 10-15 hours; for a further two it had extended to 18-21 hours; and for two couples it lasted as long as 31-36 hours.

PARENTS' RESPONSES TO MEDICAL PREDICTIONS At first interview, six families $(10 \%)$ reported being told that death would "probably be quick", but in their perception it was anything but. The five who provided information on the length of time involved reported deaths that took $1.5,7,14$, and 31 hours. In only one case were parents given a longer prediction than in reality they had: the baby died in just one hour instead of the expected seven. Although most of the protracted deaths in this study were term infants with lethal anomalies or asphyxia, for which it can be particularly difficult to make predictions, five families with preterm infants found the time taken distressing. In three of these cases, death did not ensue until 10-15 hours after treatment withdrawal.

No parent expressed regret about a rapid death. It seemed to reinforce the accuracy of the medical prognosis. Treatment had merely been prolonging the process. The wisdom of what they had decided was confirmed. On the other hand, delays made parents question the rightness of the decision to stop. If the baby was fighting so hard to live should they give him/her every chance? Was he or she trying to tell them that they wanted to live?
It seemed important to find out whether parents retained a sense of dissatisfaction over time. When asked at 13 months to reflect on the management of the dying process, very few mentioned the fine detail of what had happened. Concentration rather was on the speed with which events had happened and the parents' knowledge of the problems. At this point, eight sets of parents $(16 \%)$ regretted the length of time it had taken to make the decision to withdraw treatment; they all wished the whole process had been shorter. One couple specifically said they wished their child had been "euthanased" early on and they had all been spared the agonising experience they had endured. On the other hand, by this stage, four sets of parents $(8 \%)$ now wondered if efforts should have been made for longer to save the baby's life.

\section{SPECIFIC FACTORS THAT PARENTS FOUND} DISTRESSING

The parents were asked to identify those things that they had found helpful or unhelpful during the dying process. Against a background of appreciation of the individual care and attention they had received, and the compassionate support that had enabled them to be involved with their child and to build up memories, they identified a number of factors that they found particularly distressing. These help to explain the distress of lingering deaths.

\section{Unpleasant noises and sights}

Parents graphically described the horror they felt when the baby made unpleasant noises or appeared to be struggling to breathe. Unexpected colour changes when ventilation was discontinued distressed others. A small number of parents described being hysterical or rigid with terror, or of being unable to look at the child.

"When she was struggling (to breathe) that was the worst bit. ... the noise she was making it was like you were killing her or something - a horrible noise." (P13: father of baby with cardiac anomaly)

"He was coughing, spluttering, gasping ...the minute he (the doctor) was coming over (to check that his heart had stopped) he started again. I was just not looking ....My arm was numb. They were saying, 'Go and have a lie down, this could go on for hours.' But I couldn't even move. I was just so damned scared. I think it was more his noises that haunt me than the colour of his blue hand. It was going on forever . . It was two and a half hours." (P20: mother of severely asphyxiated baby)

\section{Delays in withdrawing because staff were not} available

Once the decision was made to stop treatment, it was distressing for parents to have the moment of implementing the decision delayed for reasons not of their choosing. A few parents had to wait some hours until there were enough staff or certain people available. In the perception of one couple, treatment withdrawal was 
postponed for four days because, they were told, it required a given expert pathologist to do the autopsy.

Failure to conform with agreed procedure When a course of action had been agreed on, it was bewildering and upsetting to parents to have it ignored. For example, one couple and the consultant had agreed that their extremely premature baby would not be resuscitated. However, a junior doctor did initiate treatment. These parents felt it was wrong that such a situation had arisen, but their retrospective gratitude for the extra time they had had with the baby softened their dissatisfaction.

\section{Lack of information}

Thirteen months after the event, the parents were less inclined to focus on the detail of their experience of the actual dying, and a noteworthy finding emerged. A fifth of the families (10/ 50) felt that they had had too little information and this had limited their capacity to make wise choices.

"If they had just told us that (there was no hope before they resuscitated him on day 6), we wouldn't have had to go through all this agony for the next three weeks until he died ... .He was really, really severely brain damaged and couldn't suck or anything so he had no quality of life and it was no use pursuing that sort of thing. To be quite honest it just prolonged the agony." (P39: parents of a severely asphyxiated baby)

\section{Non-intervention}

Three sets of parents specifically said they found it unhelpful when the doctors did not give the child something to end life sooner, to lessen the baby's suffering and their own distress. The suffering involved was a major reason given for stopping aggressive treatment for such babies. In discussing their opinions about the ending of lives in general, five sets of parents volunteered that active intervention to end the lives of children should be permissible when the decision was made to allow them to die. They saw no merit in prolonging the child's or the families' distress in these circumstances.

\section{Discussion}

It has to be remembered that these were parents speaking with the benefit of hindsight. It is much easier to say after the event that some other experience would have been better, or the time better used. We fully appreciate that at the time there are many unknowns and many sensitivities to consider.

Parents clearly feel a need to be involved in the deaths of their babies after treatment withdrawal, and missed opportunities are often subsequently regretted. They are grateful for the compassionate care provided by the medical and nursing teams, but when the death is a protracted process it causes them deep distress. It is clear from our study that parents expect the child to die soon after treatment withdrawal, and that medical predictions are not always accurate. In these cases which involve a decision to withdraw treatment, a lingering death has special significance. It raises doubts: was the decision to stop right? Is the baby not really as ill as the doctors say? Is he telling us that he wants to live? On the other hand, from the professional point of view, withdrawing treatment does not inevitably lead to death, as the RCPCH framework points out, ${ }^{1}$ and some caution is appropriate.

Our findings suggest that parents are not always well prepared for what may happen. In order to cope with the pain of the dying, they need a number of things which our respondents have highlighted. First is full information, which includes, where possible, some idea of what to expect. Second, they need an honest admission of uncertainty rather than inappropriate estimates of the time it will take. It helps them if they are given the reasons for possible delays, so that they are not left questioning the rightness of the decision to stop. Third, they need the messages to be consistent. If it becomes necessary to deviate from an agreed plan, they need to know clearly the reasons for that change of direction so that it is not perceived as inconsistency or doubt about the wisdom of the decision to stop treatment.

Parents are also giving a message that where death is the expected and desired outcome, there is no point in allowing prolonged suffering. Not only do they reflect sadly on the burden involved in aggressive and invasive procedures already gone through, but, even in the latter stages of the process when such treatment has been stopped, they perceive the baby as distressed when breathing is laboured or the child appears to struggle. Some have advocated active measures to end such a state. Many others express a gratitude for opiates being given in doses large enough to ease those symptoms.

This finding, however, raises more fundamental global questions. The law in this country prohibits active killing of human beings even in the name of mercy. Professional medical guidelines, which include those from the $\mathrm{RCPCH}^{12}$ as well as government reports, ${ }^{34}$ uphold this position. Yet the courts have demanded compassionate care and decreed that children should not suffer unnecessarily. ${ }^{14}$ Even though the exact measurement of pain is a difficult estimation for neonates, clinicians do make efforts to limit pain and to reassure parents on this point. But when death is inevitable and compassionate terminal care is required, not only the baby's comfort, but also the minimisation of the parents' distress becomes a priority. Our findings show clearly that parents are traumatised by a protracted dying process. So too are the staff. ${ }^{5}$ What then should be done with the severely asphyxiated child who requires no medical intervention, or the severely damaged baby who lingers long after treatment withdrawal? Guidelines offer little direction. ${ }^{15}$ We recognise these are extremely sensitive clinical dilemmas but suggest that perhaps, given the insights these courageous parents have provided, it is time to reopen the debate. 
CONCLUSION

From this enquiry we may conclude that lingering deaths are a distressing feature of today's management of babies after treatment withdrawal. If compassionate care is to be just that, it is crucial that we listen to the voice of parents who have lived through this painful experience. They are challenging us to look again at our current practices. Whose interests are we really serving in protracting inevitable deaths?

We are grateful to many colleagues for their contribution to this project but particularly members of the research team (Professor R Hume, Dr I A Laing, Dr D J Lloyd, Professor A G M Campbell, Dr C H M Walker, Dr K M Boyd, Mr R Bercovitch),
colleagues in the study units and in the Institute of Medical colleagues in the study units and in the Institute of Medical
Ethics. The study was funded by The Scottish Executive. Our greatest debt is to the bereaved parents who so courageously shared their experiences and insights.

1 Royal College of Paediatrics and Child Health. Withholding or withdrawing life saving treatment in children. A framework for practice. London: RCPCH, 1997.

2 British Medical Association. Withholding and withdrawing life-prolonging medical treatment. Guidance for decision making. London: BMA, 1999.
3 House of Lords Select Committee on Medical Ethics. Volume 1. Report. London: HMSO, 1994.

4 Government response to the report of the Select Committee on Medical Ethics. Cm 2553. London: HMSO, 1994.

5 McHaffie HE, Fowlie PW. Life, death and decisions: doctors and nurses reflect on neonatal practice. Cheshire: Hochland and Hochland, 1996.

6 Gustaitus R, Young EWD. A Time to be born, a time to die. Conflicts and ethics in an intensive care nursery. Reading MA: Addison Wesley, 1986.

7 Anspach RR. Deciding who lives: fateful choices in the intensivecare nursery. Berkeley: University of California Press, 1993.

8 Guillemin JH, Holmstrom LL. Mixed blessings. Intensive care for newborns. New York: Oxford University Press, 1986.

9 Frohock FM. Special care. Medical decisions at the beginning of life. Chicago: University of Chicago Press, 1986.

10 Stinson R, Stinson P. The long dying of baby Andrew. [Second printing]. New York: Little Brown and Co, 1983.

11 Benson J, Robinson-Walsh D. Love, labour and loss: stillbirth and neonatal death. London: Scarlet Press, 1996.

12 Cox O. Sunday's child. When loving means letting go. Bath: Ashgrove Press, 1988.

13 Fairbairn G. When a baby dies: a father's view. In Dickenson D, Johnson M, eds. London: Open University and Sage, 1995:290-2.

14 Campbell AGM, McHaffie HE. Prolonging life and allowing death: infants. $\mathcal{F}$ Med Ethics 1995;21:339-44.

15 McHaffie H, Fowlie PW. Withdrawing and withholding treatment: comments on new guidelines. Arch Dis Child 1998;79:1-2 